\title{
Pigmentary Disorders: More Troublesome in Skin Color
}

\section{Hsuan-Hsiang Chen*}

Department of Dermatology, Jing-Mei General Hospital, Taiwan

*Corresponding author: Hsuan-Hsiang Chen, Department of Dermatology, Jing-Mei General Hospital, Taiwan, Tel: +886-989-584-961; E-mail: beauty101@gmail.com

Received date: February 02, 2017; Accepted date: February 07, 2017; Published date: February 10, 2017

Copyright: $\odot 2017$ Chen $\mathrm{HH}$. This is an open-access article distributed under the terms of the Creative Commons Attribution License, which permits unrestricted use, distribution, and reproduction in any medium, provided the original author and source are credited.

Citation: Chen HH (2017) Pigmentary Disorders: More Troublesome in Skin Color-Journal of Pigmentary Disorders for Volume 3, Issue 3. Pigmentary Disorders 3: e107. doi:10.4172/2376-0427.1000e107

\section{Editors' Message}

One of the most exciting and fascinating features in Dermatology is the various presentation of color, distribution, morphology, pattern, and clinical course of the skin lesions. In this coming issue, we have a diversity of article themes addressing issues regarding the science of melanocytes from basic research to clinical settings.

In India, light complexion is always equated with beauty, racial superiority, and power, which strongly influences marital prospects, employment, income and social status. On the other hand, no treatment of vitiligo produces predictably good results. Needling with topical 5-fluorouracil seems promising. As for congenital melanocytic nevi among infants in Turkey, the dermoscopic patterns are more often characterized by a globular pattern and dot structure. Although the evaluation of sentinel lymph node improves the prognostic accuracy in patients with clinical stage I/II melanoma, it should be reconsidered in the melanoma patient with Anthracosis [1-3].

In regarding psoriasis vulgaris, the generally considered differential diagnoses are nummular eczema, mycosis fungoides, pityriasis rubra pilaris, dermatitis herpetiformis, and Bowen's disease. The pattern of A Disintegrin-like and Metalloprotease domain containing Thrombospondin type 1 motif-like 5 (ADAMTSL5) expression in psoriasis lesions is very similar to the infiltrating pattern of T cells and dendritic cells, which implicating its potential role as an activating antigen for IL-17-producing $\mathrm{T}$ cells in psoriasis [4-6].

As we all know, HSV-1 can infect many types of cells, especially keratinocytes. It is the first time that we realize HSV-1 can also infect melanocytes and induce melanocytes apoptosis. Finally, for treatment of the lateral upper part of the cheeks with fillers, the blunt-tip cannula is considered elegant and preferable equipment $[7,8]$.

I believe all of these articles in this issue of the Journal of Pigmentary Disorders will provide the clinical insights as well as basic knowledge about the pigment related issues.

\section{References}

1. Gonzalez AN, Estebaranz JLL, Orgaz JAR, Mitjavila M, Moraleda FP, et al. (2016) Anthracosis mimicking metastatic melanoma in a sentinel lymph node. Pigmentary Disorders 3: 1-2.

2. Anand CV (2016) India's obsession with skin fairness and whitening: why? Pigmentary Disorders 3: 1.

3. Vedamurthy M, Moorthy A, Samuel S (2016) Successful treatment of vitiligo by needling with topical 5 fluorouracil. Pigmentary Disorders 3: $1-3$.

4. Kucuk E, Guney S, Karakas AA, Alpsoy E and Yilmaz E(2016) Frequency and dermoscopic features of congenital melanocytic naevi in antalya, Turkey and review of the literature. Pigmentary Disorders 3: 1-7.

5. Bonifacio KM, Kunjravia N, Krueger JG, Duculan JF (2016) Cutaneous expression of a disintegrin-like and metalloprotease domain containing thrombospondin type 1 motif-like 5 (adamts15) in psoriasis goes beyond melanocytes. Pigmentary Disorders 3: 1-5.

6. Tuzun B (2016) The differential diagnosis of psoriasis vulgaris. Pigmentary Disorders 3: 1-2.

7. Lan J, Hong Y, Qi R, Zheng S, Gao XH(2016) HSV-1 enters melanocytes and induces their apoptosis. Pigmentary Disorders 3: 1-5.

8. Zenker S (2016) Indication specific cannula treatment. Pigmentary Disorders 3: 1-3. 